\title{
Metaheuristic techniques on cell formation in cellular manufacturing system
}

\begin{abstract}
Cellular manufacturing system is a submission of group technology wherein are different machines or processes have been combined into cells, each of which is devoted to the fabrication of a part, product family, or limited group of families. Cell formation is necessary for implementation of cellular manufacturing. Many of methods exist for cell formation problem solving. Some of these methods are applying in traditional cell design, in fixed routines and others are applying in dynamic cells environment. In this review article, critical assessment of various metaheuristic techniques which utilized in cell formation problem solving is made through extensive literature review. Various existing models for cell formation are argued consequently and directions for future work are presented.
\end{abstract}

Keyword: Metaheuristics; Cell formation; Cellular manufacturing system 